\title{
A Personal Respirator Specification for Health-care Workers Treating COVID-19 (PeRSo)
}

Paul T. Elkington ${ }^{1,2,3 *}$, Alexander S. Dickinson ${ }^{2,4}$, Mark N. Mavrogordato ${ }^{4}$, Daniel C. Spencer ${ }^{5}$, Richard J. Gillams ${ }^{5}$, Antonio De Grazia ${ }^{4}$, Sebastian Rosini ${ }^{4}$, Diana Garay Baquero ${ }^{1,3}$, Laura E. Diment ${ }^{4}$, Nitin Mahobia ${ }^{6}$ \& Hywel Morgan ${ }^{2,5}$

${ }^{1}$ School of Clinical and Experimental Sciences, Faculty of Medicine, University of Southampton, UK.

${ }^{2}$ Institute for Life Sciences, University of Southampton, UK.

${ }^{3}$ NIHR Biomedical Research Centre, University Hospital Southampton NHS Foundation Trust, Southampton, UK.

${ }^{4}$ Mechanical Engineering Department, Faculty of Engineering \& Physical Sciences, University of Southampton, UK

${ }^{5}$ School of Electronics \& Computer Science, Faculty of Engineering \& Physical Sciences, University of Southampton, UK

${ }^{6}$ Department of Infection, University Hospital Southampton NHS Foundation Trust, Southampton, UK.

*Corresponding author: P.Elkington@soton.ac.uk

This is a draft paper published on engrXiv as a pre-print, recognising the urgency of sharing this information at the current stage of the COVID-19 pandemic. This paper will be revised as further information becomes available.

Version $0.1 \quad 6^{\text {th }}$ April 2020: First Draft Release

Version $0.2 \quad 7^{\text {th }}$ April 2020: Typos corrected and Results updated.

Version $0.3 \quad 8^{\text {th }}$ April 2020: Power supply example updated.

Version $0.420^{\text {th }}$ May 2020: Component nomenclature updated to match BS/EN 12941. Prototype weight distribution between belt- and head-mounted components added. Funding acknowledgments, raw data statement and author details updated.

\section{Acknowledgements:}

Wassim Dbouk, Diana Galpin, Gareth Giles, Nick Hale, Chris Malcolm, Alexandra Mant, Matt Mowlem, Roel Mingels of the University of Southampton; The Institute for Life Sciences (IfLS); $\mu$ VIS X-ray Imaging Centre at the University of Southampton (Engineering and Physical Sciences Research Council grant EP-H01506X); and Matt Wells and Steve Foster of McLaren Racing Ltd., for support on design of connectors and headband elements.

We gratefully acknowledge support from projects that seconded staff to this work including MRC (MR/P023754/1 (PTE)), EPSRC (EP/L025035/1 (ADG) and EP/R014213/1 (ASD, LED)), and donations to the Southampton Coronavirus Response Fund.

Additional data has been made openly available from the University of Southampton repository at https://doi.org/10.5258/SOTON/D1300.

Please see Warning and Disclaimer at the end of this document. 
Abstract

The SARS-CoV-2 virus infection is a rapidly spreading global pandemic. Recent media coverage has highlighted the importance of protecting health-care workers together with issues surrounding availability and suitability of Personal Protective Equipment (PPE). Around 20\% of healthcare workers treating COVID19 cases in Italy have become infected which leads to staff absence at a critical point during the pandemic, and unfortunately in some cases mortality.

PPE plays a major role in control programs. Standard PPE such as N95/FFP3 facemasks have limitations such as an ineffective seal during talking or after prolonged use, face shapes which cannot be adequately fitted, and logistical issues ensuring availability of the correct mask for each person. Furthermore, global stock is low, and issues around diagnostic testing specificity and turnaround time may lead to infectious patients receiving care from health care staff who are not wearing appropriate PPE.

To address acute shortcomings in PPE availability, we have developed a simple pressurised air purified respirator unit, incorporating a combination of inexpensive and widely available components parts. The prototype was developed to minimise the number and complexity of manufacturing steps with the intention that derivative versions could be developed in many different parts of the world, including low resource settings with minor modification, where transmission could be rapid amongst high population densities.

The "Personal Respirator - Southampton" (PeRSo) delivers HEPA filtered air from a battery powered blower fan-filter assembly through a lightweight hood/face mask that can be comfortably worn for several hours. Initial user feedback provided by doctors and nurses shows the PeRSo prototype was preferred to standard N95/FFP3 masks, being more comfortable, reducing time lost placing and removing PPE between patients, and allowing better communication. Preliminary tests indicate that the device removes microbes and passes the "fit tests" widely used to evaluate face masks. Full verification of the safety and the duration of effectiveness and durability of the device is required, as part of translation into use. Rapid upscale of production is required to protect healthcare workers from infection while the global situation accelerates, so that they can look after patients during the peak of the pandemic. 


\section{Introduction:}

In light of the rapidly spreading SARS-CoV-2 pandemic, there is an urgent need to protect health-care workers (HCW) from inadvertent infection; the Lancet ${ }^{1}$ states that health-care workers are "every country's most valuable resource". Currently around $20 \%$ of HCWs treating COVID19 cases in Italy have become infected ${ }^{2}$, making up $9 \%$ of the country's cases. ${ }^{3}$ This leads to significant staff absence and unfortunately in some cases mortality at a critical point during the pandemic.

In the early part of a response to pandemics such as this, where vaccination is not available, protective equipment plays a major role in control programs. A review of the efficacy of protective equipment during the SARS outbreak in hospital settings showed that failure to implement necessary barrier precautions was responsible for nosocomial transmission. ${ }^{4}$ Current Personal Protective Equipment (PPE) is disposable and in short supply and there are issues around suitability. HCWs may receive limited PPE provision, fit testing and training prior to a pandemic. ${ }^{5}$ During the current pandemic global stock of PPE is low. In high incidence areas such as Italy supplies of PPE ran out in some hospitals, and UK guidelines on how PPE should be used have been updated. ${ }^{6}$ Where patient testing is limited or viral load is below the limit of detection in recently exposed individuals, ${ }^{7}$ false negative results lead to infectious patients receiving care on wards where no PPE is worn.

PPE is selected by considering the route of disease transmission (e.g. airborne, droplet or contact). ${ }^{8}$ COVID-19 infection is primarily transmitted by droplets and fomites transmitted by face touching, although it is also envisaged that there may be an airborne infection route for HCW performing aerosol-generating procedures in health-care settings. ${ }^{9}$ Respiratory Protective Equipment (RPE) or respirators that can be continuously worn by front-line health staff provide protection against air-borne pathogens, as well as a physical or psychological barrier to avoid transmission from surfaces and fomites. The main RPE categories are the filtering facepiece respirator (FFR, i.e. N95/FFP3), full facepiece respirator (which features an integrated screen or visor fitted around the face), and the powered air purifying respirator (PAPR).

Filtering facepiece respirator masks are designed to protect HCWs from possible infection from treating patients, as distinct from surgical masks which are intended to protect others from the wearer. ${ }^{10}$ Scientific literature documents limitations for N95/FFP3 masks including pressure and thermal discomfort after long-term use, failure of the facemask seal whilst talking, certain face shapes to which the available mask range do not fit. ${ }^{11-13}$ The Standard defining FFR efficiency allows $5 \%$ inward leakage maximum, and $1 \%$ aerosol filter penetration by $0.02-2 \mu \mathrm{m}$ (median $0.6 \mu \mathrm{m}$ ) particles. $^{14}$

Full-face respirators and respirators with hoods are reported to offer greater respiratory protection and more facial coverage against splash than FFRs. ${ }^{8}$ Where an elastomeric full-face respirator may cause skin discomfort, rashes and oedema if worn for long periods, hood-type PAPR devices are reported to be more comfortable by delivering a continuous airflow. ${ }^{15}$ Furthermore a hood limits inadvertent facial touching by the healthcare worker, avoids issues of compromised fit between masks and goggles, and by removing the need to change the RPE between patients the clinician's work can be much more efficient. All these devices are subject to logistical issues with delivery of adequate supplies for each person.

To address acute shortcomings in PPE availability, we have developed a simple purified air respirator that is made from inexpensive and widely available component parts. The prototype has few manufacturing steps so that derivative versions can be developed for use in low resource settings with minor modification. 


\section{Methodology:}

Figure 1 is a sketch of the initial concept, showing a filter with pre-filter, blower fan and power supply all worn on a belt pack, plus a breathing hose, head harness, and enclosed hood with visor.

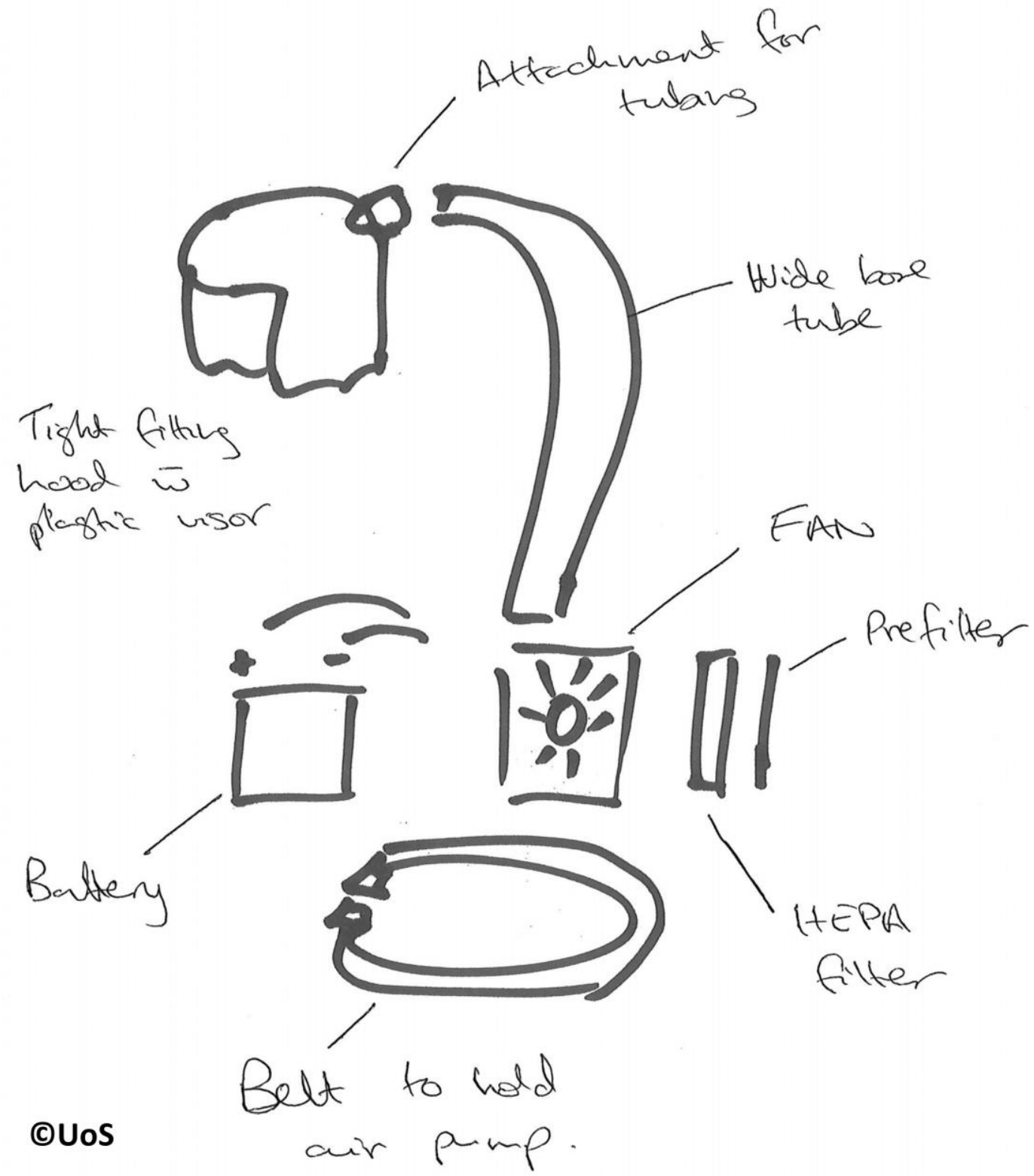

Figure 1: Sketched System Diagram for a Powered Air Purifying Respirator (PAPR).

Clinical staff at University Hospital Southampton NHS Foundation Trust provided initial user needs statements for a PAPR respirator designed to replace passive FFP3 masks and surgical masks, with respiratory- and droplet splashprotective capability to the Standard of BS EN12941. ${ }^{16}$ The respirator should be made from inexpensive and widely available component parts where possible, to address supply chain problems with commercial devices. It had to be comfortable to wear for an 8 hour shift with one break, and be stable during use, including moving around the hospital, bending and performing cardio-pulmonary resuscitation (CPR). The hood and visor needed to provide full vision for the user and minimise hearing impairment, as well as providing patients and colleagues with full face visibility. Regarding practical use it needed to be reusable over the duration of the pandemic, ideally for a period of 6 months, and therefore easily decontaminated and cleaned. Practically it should be easily put on and taken off ('donned and doffed') with assistance. The components should ideally be low profile, and the belt-mounted unit worn over medical 'scrubs' clothing but underneath a front loading gown or apron, and covered with a cleanable cover or 
cowl. These requirements were provided by staff with experience of using other commercially available PAPR devices, and thus represent the specific requirements of a PAPR device for healthcare workers in the COVID-19 pandemic situation, only some of which are expressed in the general PAPR Standard. ${ }^{16}$ These user needs were translated into the following technical specification expressed in Table 1:

Table 1: The PeRSo Open Specification is summarised as follows:

\begin{tabular}{|c|c|}
\hline Component & Description \& Example Embodiment \\
\hline Waterproofing/Cleaning & $\begin{array}{l}\text { - System must be water resistant to cleaning with } 1000 \mathrm{ppm} \text { chlorine, for example spraying cloth } \\
\text { with solution and wiping down. }\end{array}$ \\
\hline Filter \& Housing & $\begin{array}{l}\text { - High-Efficiency Particulate Air (HEPA) filter }{ }^{17} \text {, ideally H13 or H14; potentially sourced from a } \\
\text { vacuum cleaner, dehumidifier or equivalent; } \\
\text { - Prefilter for large particles; } \\
\text { - Robust protective cover to avoid knocks, puncture and moisture ingress during cleaning. }\end{array}$ \\
\hline Blower & $\begin{array}{l}\text { - Centrifugal fan delivering }>170 \mathrm{I} / \mathrm{min}^{18} \text { at the system backpressure, depending on choice of } \\
\text { filter, breathing hose and tubing in headgear. }\end{array}$ \\
\hline Power supply & $\begin{array}{l}\text { - Rechargeable batteries or battery pack; } \\
\text { - Minimum } 4 \text { hour runtime, ideally }>12 \mathrm{hrs} \text {; } \\
\text { - E.g. The selected fan running at } 7.2 \mathrm{~V} \text { draws } ~ 0.2 \mathrm{~A} ; 2.4 \mathrm{Ah} \mathrm{NiMH} \text { batteries give a runtime } 12 \mathrm{hrs} \text {; } \\
\text { - On/off switch, protected for cleaning and to avoid accidental power-off; } \\
\text { - Ideally includes a low-power warning with }>15 \text { min runtime. }\end{array}$ \\
\hline $\begin{array}{l}\text { Blower Unit Housing and } \\
\text { waist band or backpack }\end{array}$ & $\begin{array}{l}\text { - Airtight assembly to mount filters to fan; runner's belt bag or backpack; } \\
\text { - Covered using a cleanable or disposable cowl. }\end{array}$ \\
\hline Breathing hose & $\begin{array}{l}\text { - Low mass and high flexibility to provide minimal impedance to head movements and strain on } \\
\text { neck muscles; } \\
\text { - Either cut to length for user or length-adjustable, } \\
\text { - Ideally medical grade material e.g. polyurethane, PVC. } \\
\text { - Typical inner diameter } 25-32 \mathrm{~mm} \text {. }\end{array}$ \\
\hline Connectors & $\begin{array}{l}\text { - Screw or bayonet type; potentially with internal helix matching thread formed by } \\
\text { reinforcement on breathing hose. } \\
\text { - Ideally uniform connection between blower unit and breathing hose so blower unit can be } \\
\text { exchanged between users between shifts after appropriate decontamination }\end{array}$ \\
\hline Head harness & $\begin{array}{l}\text { - Comfortable use for an } 8 \text { hour shift, avoiding direct contact with facial skin; } \\
\text { - Adjustable to different head sizes and shapes; } \\
\text { - Allowing support of breathing hose; } \\
\text { - Easily attachable and removeable mounting of hood }\end{array}$ \\
\hline Hood & $\begin{array}{l}\text { - Hydrophobic material, (e.g. Tyvek, Vent3 polypropylene breather membrane); } \\
\text { - Latex-free; } \\
\text { - Taped or stitched transparent polymer visor (e.g. PVC, polycarbonate), optically clear and } \\
\text { resistant to fogging; } \\
\text { - Probably multiple use but single-user, with label showing user's name and role to aid } \\
\text { identification. } \\
\text { - For a positive pressure PAPR device, the hood, face/neck seal and tube connector do not need } \\
\text { to be air-tight, as the clean airflow would prevent ingress of contaminants }\end{array}$ \\
\hline
\end{tabular}

\section{Candidate Component Types:}

The reasons for selecting general types of component are provided below, although individual components are not identified as the available products and resources will vary considerably between hospitals, settings and budgets. Only key components are described in the following paragraphs, where explanation of the details in Table 1 is beneficial.

Filters: Excellent bacterial and viral filtering performance has been demonstrated through use of HEPA (High Efficiency Particulate Air) filters. ${ }^{19}$ HEPA is usually produced from microfiber glass. The HEPA filter standard specifies removal of at least $99.95 \%$ (H13 grade) and $99.995 \%$ (H14 grade) of particles with diameters greater than $0.3 \mu \mathrm{m}$, near to the Most Penetrating Particle Size (MPPS). ${ }^{17}$ Various mechanisms play a role in the filtration efficiency such as the depth of the filter layer, the density of the fibres, and the velocity of the gas to be filtered, and the above efficiencies are tested and valid at the designer's specified nominal flow-rate. In most general terms, HEPA filters impede larger particles by interception and impaction on filter fibres and smaller particles by diffusion processes. ${ }^{20}$ Both 
mechanisms are potentially relevant in this case: particles ranging in size from 0.01 to $500 \mu \mathrm{m}$ are generated in breathing, coughing, sneezing and talking, ${ }^{21}$ and coronavirus virions are reported to range from 0.05 to $0.15 \mu \mathrm{m}$ in diameter with average diameters around 0.08 to $0.09 \mu \mathrm{m}^{22,23} \mathrm{HEPA}$ filters capture wide range of particles efficiently, and these characteristics make HEPA filters a sound option for use in respirators that are intended to protect against COVID-19 droplet and aerosol transmission infection.

Blower Fan: Centrifugal fans are preferable to axial fans for the blower, because they can generate higher pressure to overcome the pressure drop across the filter and the breathing hose. They are quieter, deliver a more constant flow, with reasonably low power consumption.

Head harness: The protective headgear can be made using components from an off-the-shelf browguard or hard hat, which provides an adjustable, comfortable support for the breathing hose and visor.

Connectors: A practical means to address logistical and supply issues, and provide flexible implementation of this specification in low resource settings, we propose universal connectors between the rest of the components. Universal screw-fit or bayonet connectors may allow assembly of different blower fans, breathing hose, and headgear. Furthermore, connecting the hood's visor to the head harness using adhesive Velcro allows easy hood removal for cleaning and replacement, and use of different hoods for different levels of protection. For example, anaesthetists performing aerosol-generating procedures like intubation may prefer to use hoods providing greater coverage of the neck and shoulders.

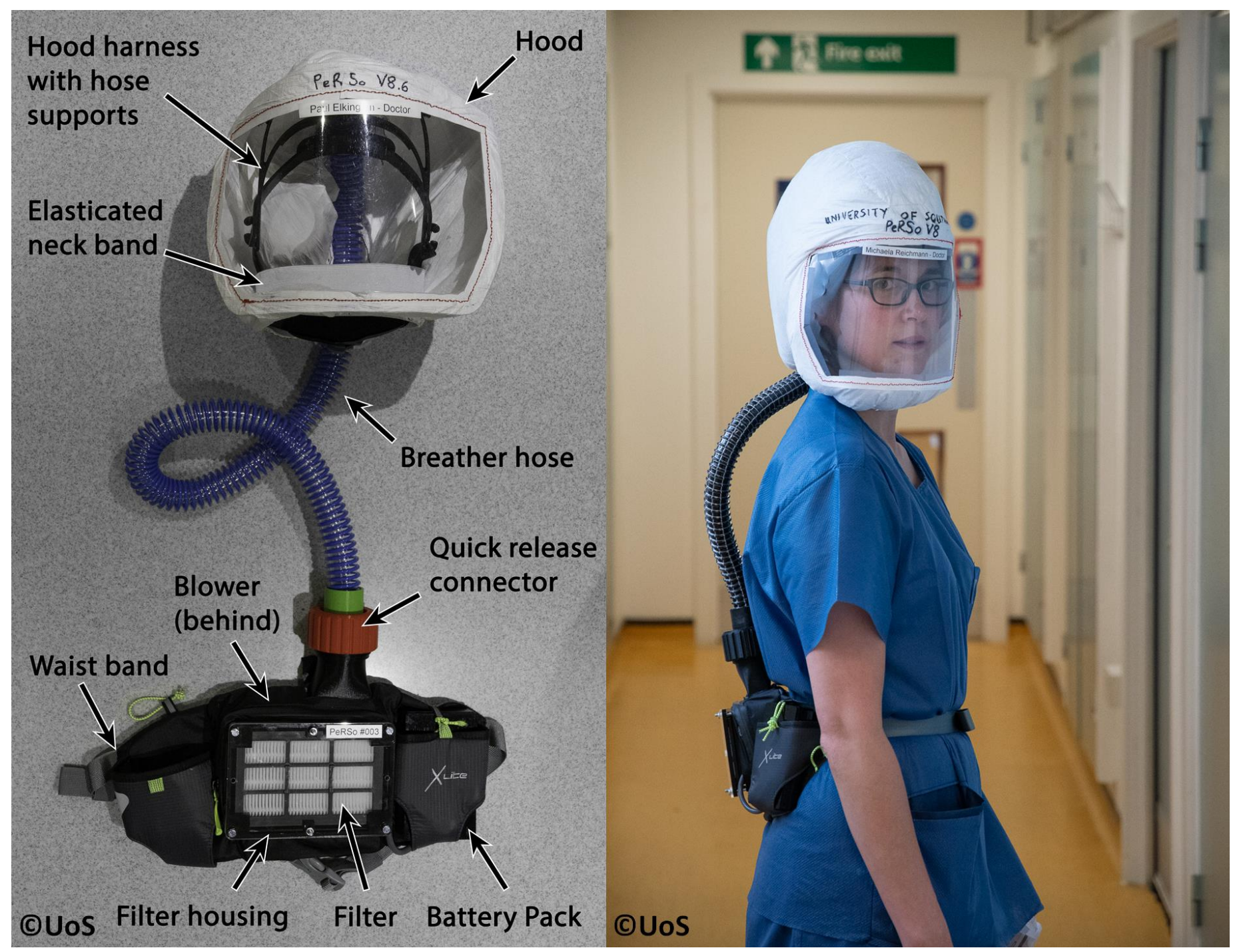

Figure 2: Prototype PeRSo Respirator system layout (left), and donned by a user to show ergonomics (right). 
The prototype PeRSo device is shown in Figure 2Figure 1 and Figure 3a was assembled using a widely available 10W $12 \mathrm{~V}$ centrifugal fan, a vacuum cleaner HEPA filter, corrugated plastic breathing hose, and a customised harness designed by McLaren Racing Ltd (Figure 3b). This featured a head band 3D printed by filament deposition modelling (FDM) in ASA (Acrylonitrile styrene acrylate) material, with adjustable rubber straps, and breathing hose clip and duct components 3D printed in chopped carbon fibre filled Nylon (CF12) and ABS (Acrylonitrile butadiene styrene). The fan and filter housing was produced from a stack of laser cut $3 \mathrm{~mm}$ acrylic sheet that provided an air-tight interface (Figure 3c). The interface between the fan and acrylic was sealed with silicone sealant. A threaded connector was designed to join the breathing hose and fan outlet, 3D printed by FDM in PLA (polylactic acid). The breathing hose was mounted on the headband with 3D printed clips, and its open end crimped at the forehead in order to diffuse the airflow over the visor and the user's face. A hood was made from Tyvek material cut from a standard protective coat, with a $0.25 \mathrm{~mm}$ PVC visor and elasticated neck band, influenced by the principle of existing laboratory hoods available on the market. The fan, filter and power assembly unit was worn around the waist in a runner's belt-bag. The finished assembly weighed $1.39 \mathrm{~kg}$, split as $0.95 \mathrm{~kg}$ from the belt-mounted components and $0.44 \mathrm{~kg}$ for the head-mounted components and breathing hose.

a)

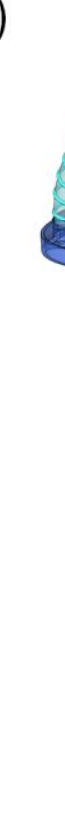

CUoS

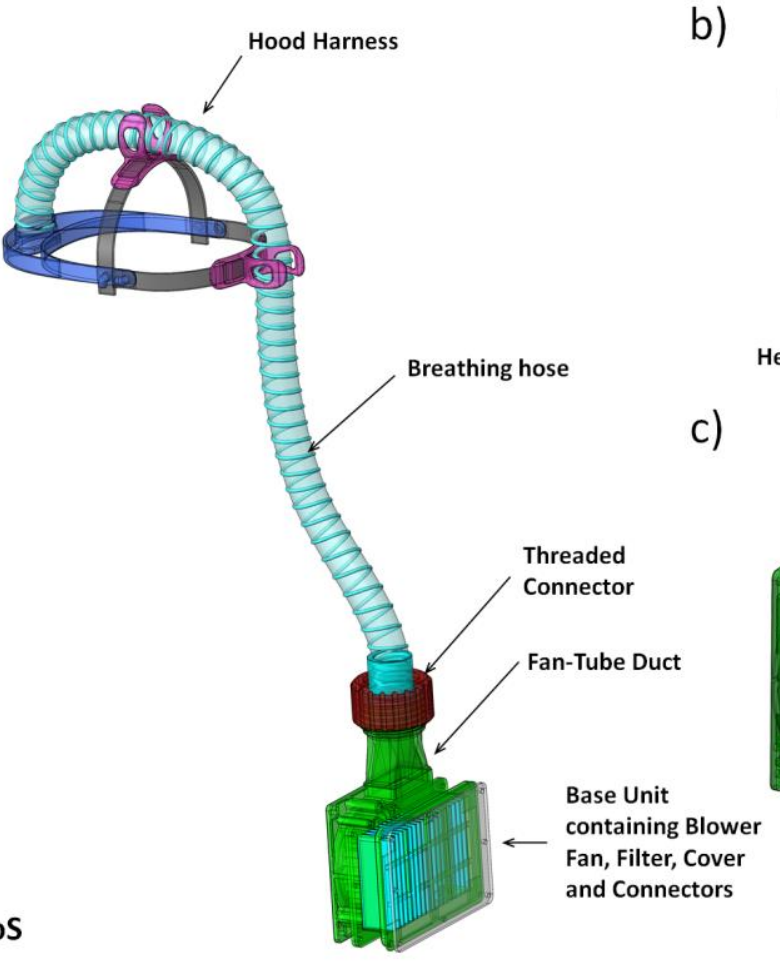

b)
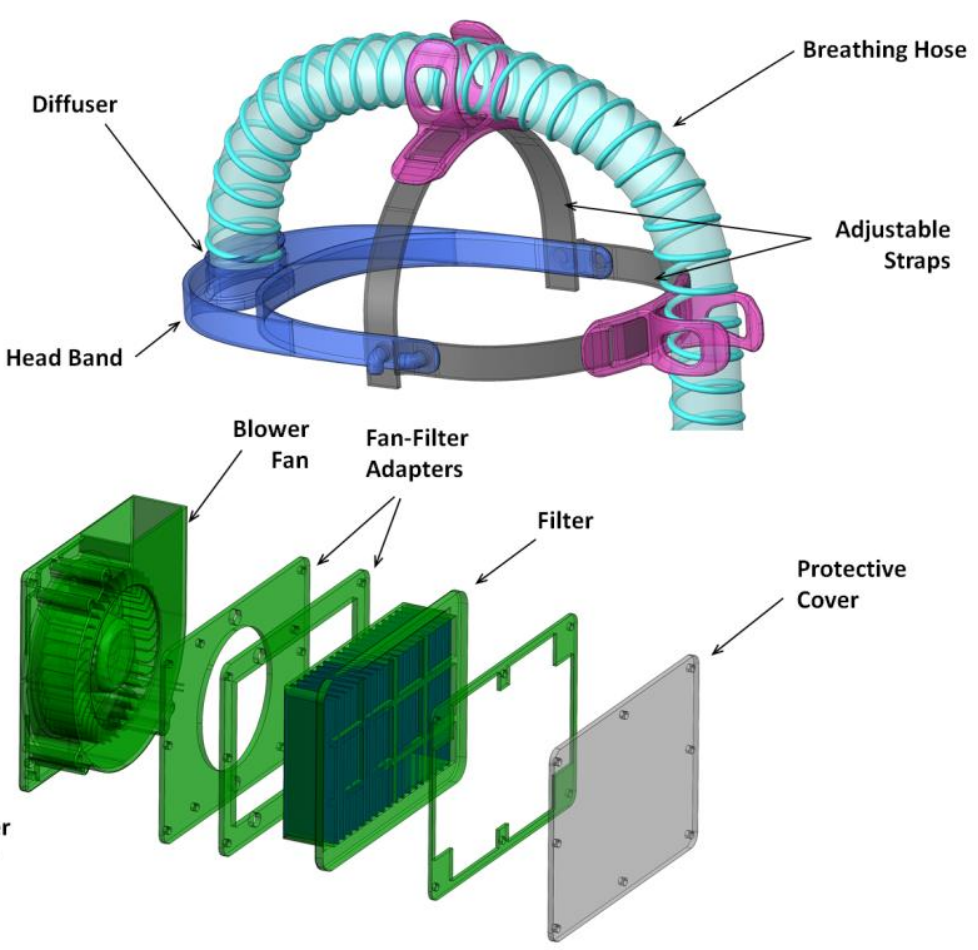

Figure 3: Renderings of key functional components a) overall system with hood removed; b) hood harness including head band and attachments to breathing hose; components 3D printed in first prototype; and c) blower unit assembly including fan-filter interface stack and protective cover from laser cut acrylic.

\section{Initial Results:}

Fit and Air-Tightness Tests: a qualitative fit test was conducted using 3M FT-30 \& FT-32 solution and spray apparatus, to assess the efficacy of the pressurised air portions of the device. No taste was identified during operation by three assessors, when the test solution was either sprayed directly onto the HEPA filter of the blower unit, or sprayed at the hood. A positive control test was then conducted by switching the blower unit off and spraying the solution onto the inside of the visor mask, which gave positive results in all three assessors. Where the spray test represented fomite droplets, the hood test was repeated with cigarette smoke with its much finer particle size (averaging 0.09$0.3 \mu \mathrm{m}$, with many smaller particles in the distribution) ${ }^{24}$ and again no penetration was detected by the wearer. 
Biological filtration efficacy: A quantitative assessment of microbiological air filtration was performed using passive sampling with settle plates according to ISO14698, ${ }^{25}$ by placing a Blood Agar culture plate within the respirator hood. A settle plate was placed outside as a positive control. The respirator was activated for 6 minutes to deliver the Standard-specified 1000 litres of room air through the blower unit onto the agar plate. The culture plate was read for bacterial growth after 24 hours of incubation at $37^{\circ} \mathrm{C}$. The control plate had ten colonies of bacteria, whereas the culture plate inside the head piece had no growth, equivalent to 0 CFU (colony forming unit) per cubic meter of air (Figure 4). This preliminary test suggests that the respirator was performing as intended in terms of bacterial filtration from ambient air, to an equivalent standard expected from an operation theatre environment. ${ }^{26}$

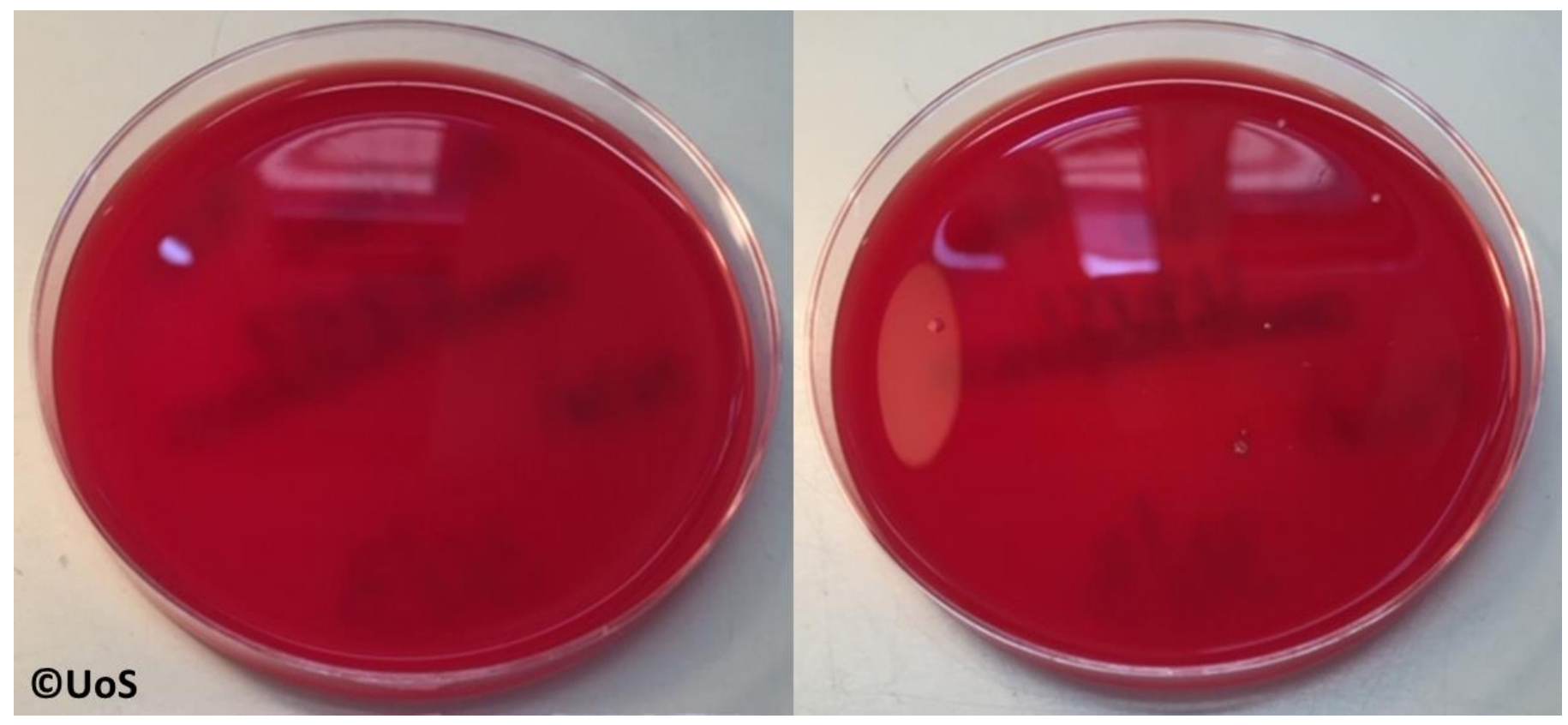

Figure 4: Test (left) and Control (right) plates, showing 0 and 10 colony forming units of bacteria per cubic metre of air, respectively.

Healthcare Worker Feedback: Respiratory physicians and nurses provided user feedback on PeRSo prototypes whilst working standard shifts on NHS wards. Doctors commented on the advantage of not needing to change PPE frequently, which makes work much more efficient, and the perception of improved protection given when on wards where FFP3 face masks are not used, such as COVID-19 unknown wards. One nurse who had worked during the SARS epidemic commented that the flow of air down the face was much more comfortable than an FFP3 mask for long term use. Other user comments included themes around:

- Comfort and endurance: "Masks are hot and this was cool and not claustrophobic. By the end of yesterday staff were saying the normal mask straps were making the top of their ears sore but this wouldn't have done that."; "Brilliant! Used for over 8 hours yesterday and battery still going strong."; "A few teething issues but overall I would be happy to wear it again"

- Confidence: "Good. Felt safe"; "On asking a group of health care assistants what they thought, they all thought it was a good idea and wanted one as they did not feel safe" (Acute Medical Unit COVID ward)"

- Communication: "Was easy (in some ways better than masks) to communicate"; "Compared with mouth/nose mask, nice to see faces, helps with communication." Others noted that there was some impedance to hearing which may present challenges in hearing weaker patients, and for telephone calls.

- User experience: "Removal of PPE is often a high risk point for accidental nosocomial infection. By not having to change PPE all the time, I felt safer and was able to deliver my clinical duties much more effectively".

- Scope for Improvement: Some tasks were more difficult, notably manual heart rate monitoring by nurses using a stethoscope, outside critical care areas where heart monitors are used. 


\section{Discussion}

We report the development of an Open Specification and example prototype for a personal respirator that delivers HEPA filtered air to a hood. The design is relatively simple, components are inexpensive and where newly designed components were required, considerations for mass production have been incorporated. Preliminary tests and initial user evaluation have been positive, however, moving from established healthcare PPE protocols to a new system requires a careful evaluation of risk. At the time of writing this prototype had not been fully tested to BS EN $12941^{16}$ or approved by the Health and Safety Executive (HSE, UK). The presented tests are short-term, and the next requirement is to demonstrate safety and the duration of effectiveness and durability of the device and its component parts.

The UK Government has recently published new guidance clarifying approval of PPE, ${ }^{27}$ which draws on BS EN 12941 for loose fitting respiratory protective equipment. ${ }^{16}$ This standard includes a wide range of verification tests beyond filtration efficacy such as hose and coupling strength, hood leakage, breathing resistance, field of vision, noise, and resistance to flame. At the time of writing the UK Government's Department for Business, Energy and Industrial Strategy has instructed the Health and Safety Executive to engage in 'regulatory easing' for new market entrants of non-novel PPE. In this current regime respiratory protective equipment designed and in early testing to BS EN 12941 can be translated swiftly from prototype to product while testing is ongoing.

The prototype respirator should at minimum represent an improvement in protection over FFP3/N95 masks in terms of the percentage of airborne droplets captured, and therefore reduce an individual's exposure to viral load. Other advantages over mask-type FFR devices are comfort and skin health, temperature, communication (except perhaps by telephone), eye protection, avoidance of the user touching their own face, and lower breathing resistance. The disadvantage of any full hood-type respirator is that over-the-head aprons can take time to put on, and a stethoscope cannot be worn.

Hood type respirators require different protocols for clinical use to FFP3/N95 masks. Different approaches are required for putting the device on and taking it off, with health care staff training to avoid increasing the risk of viral exposure. ${ }^{28}$ 'Doffing stations' for removal or respirators could be established where healthcare workers are assisted with decontamination by wiping down with chlorine, by support staff also wearing adequate PPE. Without these careful use protocols personal respirators could do more harm than good, and members of the general public and untrained clinicians should not use these devices as they may inadvertently contaminate themselves.

Beyond the necessary approvals and regulations for providing these devices, researchers should also be aware of intellectual property and copyright issues if they are directly reverse-engineering existing devices. In the present work we have avoided direct reverse-engineering, motivated by developing a lower-cost accessible device made from offthe-shelf components where possible. However, we have not undertaken a full international freedom to operate search. Where others may not have this option, or be driven to reverse-engineer in order to address acute supply shortages alone, governments may be able to invoke legislation like Crown Use Exemption to authorise use of IP without the owner's agreement, or the World Trade Organisation's Agreement on Trade Related Aspects of Intellectual Property Rights. However, well-meaning individuals should be aware of these legal risks, and not rely upon the negative publicity providing a short-term deterrent to intellectual property owners taking action over infringement. ${ }^{29}$

To the best of our knowledge, powered air respirators have not been widely implemented. We propose that the PeRSo could be deployed within a tertiary care environment. We suggest that there has to be a full evaluation of a) health economic benefit, b) economics of using a non-disposable system in terms of absolute cost to the healthcare provider, c) improvement in wellbeing of staff, d) whether the device reduces infection, and e) effect on inpatient standardised mortality. 
User assessment will require different assessment for different cultural settings especially in consideration of lower and middle income countries (LMICs). Significant obstacles are financial, supply chain and mass manufacture, logistical implementation and cultural. A detailed implementation plan including features such as placing and removal protocol, battery recharging, cleaning and maintenance will be required to ensure ongoing protection during the pandemic.

\section{Conclusion:}

The PeRSo provides multiple potential improvements to current PPE provision. It may address supply chain problems especially in low resource settings where device shortages may be most acute. Other benefits include circumventing, face fit testing failure for FFP3 masks and leakage during use, coverage of the whole face, ease of movement between patients without changing PPE, and overall user experience. Many of the components are commercially available and relatively cheap, and new parts can be mass produced. Major governmental engineering efforts have gone into developing more ventilators, and we propose that the next clear effort should aim for prevention of infection. Fully developed, the PeRSo device should reduce mortality by improving efficiency of medical healthcare staff to look after more patients, and concurrently reducing staff illness and mortality. The authors are working urgently to collaborate with partners to upscale the manufacturing pipeline.

\section{References}

1. Editorial. COVID-19: protecting health-care workers. Lancet. 2020;395:922. doi:10.1016/S0140-6736(20)30644-9

2. Remuzzi A, Remuzzi G. COVID-19 and Italy: what next? Lancet. 2020;2:10-13. doi:10.1016/s0140-6736(20)306279

3. High Proportion of Healthcare Workers with COVID-19 in Italy Is a Stark Warning to the World: Protecting Nurses and Their Colleagues Must Be the Number One Priority. International Council of Nurses, Geneva, Switzerland; 2020. https://www.icn.ch/sites/default/files/inline-files/PR_09_COVID-19 - Italy.pdf.

4. Gamage B, Moore D, Copes R, Yassi A, Bryce E. Protecting health care workers from SARS and other respiratory pathogens : A review of the infection control literature. AJIC Am J Infect Control. 2005;33:114-121. doi:10.1016/j.ajic.2004.12.002

5. Chughtai AA, Seale H, Rawlinson WD, Kunasekaran M, Maclntyre CR. Selection and Use of Respiratory Protection by Healthcare Workers to Protect from Infectious Diseases in Hospital Settings. Ann Work Expo Heal. 2020;In Press. https://doi.org/10.1093/annweh/wxaa020.

6. Recommended PPE for Healthcare Workers by Secondary Care Inpatient Clinical Setting, NHS and Independent Sector. Public Health England; 2020.

https://assets.publishing.service.gov.uk/government/uploads/system/uploads/attachment_data/file/877728/T1 _Recommended_PPE_for_healthcare_workers_by_secondary_care_clinical_context_poster.pdf.

7. Fact Sheet for Healthcare Providers: CDC - 2019-NCoV Real-Time RT-PCR Diagnostic Panel. Centres for Disease Control, Atlanta, Georgia; 2020. https://www.fda.gov/media/134920/download.

8. Jones RM, Bleasdale SC, Maita D, Brosseau LM. A systematic risk-based strategy to select personal protective equipment for infectious diseases. Am J Infect Control. 2020;48(1):46-51. doi:10.1016/j.ajic.2019.06.023

9. Report of the WHO-China Joint Mission on Coronavirus Disease 2019 ( COVID-19). World Health Organisation, Geneva, Switzerland; 2020. https://www.who.int/docs/default-source/coronaviruse/who-china-joint-missionon-covid-19-final-report.pdf.

10. Goldfrank LR, Liverman CT. Preparing for an Influenza Pandemic. Personal Protective Equipment for Healthcare Workers. Washington DC: The National Academies Press; 2008.

11. Radonovich $L$, Cheng J, Shenal B V, Hodgson M, Bender BS. Respirator tolerance in health care workers. JAMA. 2009;301(1):36-38. 
12. Larson EL, Liverman CT. Preventing Transmission of Pandemic Influenza and Other Viral Respiratory Diseases: Personal Protective Equipment for Healthcare Workers: Update 2010. National Academies Press; 2011.

13. Baig AS, Knapp C, Eagan AE, Radonovich L. Health care workers ' views about respirator use and features that should be included in the next generation of respirators. Am J Infect Control. 2010;38(1):18-25. doi:10.1016/j.ajic.2009.09.005

14. BS EN 149:2001+A1:2009 Respiratory Protective Devices - Filtering Half Masks to Protect against Particles Requirements, Testing, Marking. Vol 3. London: British Standards Institution; 2009.

15. Johnson AT. Respirator masks protect health but impact performance: A review. J Biol Eng. 2016;10(1):1-12. doi:10.1186/s13036-016-0025-4

16. PrEN 12941:2016 Respiratory Protective Devices - Powered Filtering Devices Incorporating a Helmet or a Hood Requirements, Testing, Marking. London: British Standards Institution; 2016.

17. BS EN 1822-1:2009 High Efficiency Air Filters (EPA, HEPA and ULPA). Part 1: Classification, Performance Testing, Marking. London: British Standards Institution; 2009.

18. Code of Federal Regulations 42 Part 84: Approval of Respiratory Protective Devices. Washington DC: Office of the Federal Register; 2019.

19. Wilkes AR, Benbough JE, Speight SE, Harmer M. The bacterial and viral filtration performance of breathing system filters. Anaesthesia. 2000;55:458-465.

20. Perry JL, Agui JH, Vijayakumar R. NASA/TM-2016-218224: Submicron and Nanoparticulate Matter Removal by HEPA-Rated Media Filters and Packed Beds of Granular Materials. NASA, Hampton, VA; 2016.

21. Gralton J, Tovey E, McLaws ML, Rawlinson WD. The role of particle size in aerosolised pathogen transmission: A review. J Infect. 2011;62(1):1-13. doi:10.1016/j.jinf.2010.11.010

22. Goldsmith CS, Tatti KM, Ksiazek TG, et al. Ultrastructural Characterization of SARS Coronavirus. CDC Emerg Infect Dis. 2004;10(2):320-326.

23. Neuman BW, Adair BD, Yoshioka C, et al. Supramolecular Architecture of Severe Acute Respiratory Syndrome Coronavirus Revealed by Electron Cryomicroscopy. J Virol. 2006;80(16):7918-7928. doi:10.1128/JVI.00645-06

24. Bernstein DM. A review of the influence of particle size, puff volume, and inhalation pattern on the deposition of cigarette smoke particles in the respiratory tract. Inhal Toxicol. 2004;16(10):675-689.

doi:10.1080/08958370490476587

25. BS EN ISO 14698-1:2003 Cleanrooms and Associated Controlled Environments - Biocontamination Control. London: British Standards Institution; 2003.

26. Napoli C, Marcotrigiano V, Montagna MT. Air sampling procedures to evaluate microbial contamination : a comparison between active and passive methods in operating theatres. BMC Public Health. 2012;12(1):594. doi:10.1186/1471-2458-12-594

27. Specification for Gowns, Surgical Face Mask, Respirator Masks and Eye Protection (PPE). UK Government: Cabinet Office and Department of Health and Social Care; 2020.

https://www.gov.uk/government/publications/technical-specifications-for-personal-protective-equipment-ppe.

28. Weber DJ, Rutala WA, Fischer WA, Kanamori H, Sickbert-Bennett EE. Emerging infectious diseases: Focus on infection control issues for novel coronaviruses (Severe Acute Respiratory Syndrome-CoV and Middle East Respiratory Syndrome-CoV), hemorrhagic fever viruses (Lassa and Ebola), and highly pathogenic avian influenza vi. AJIC Am J Infect Control. 2016;44(5):91-100. doi:10.1016/j.ajic.2015.11.018

29. Fletcher M, Livesey N. Coronavirus: manufacturing change in the fight against COVID-19. OUT-LAW. March 2020. https://www.pinsentmasons.com/out-law/analysis/coronavirus-manufacturing-change-covid-19. 
WARNING

PeRSo is a prototype and this Specification is for information purposes only. It has not been properly tested for safety, efficacy or durability whether for single, multiple or repeated use. We have not obtained CE certification, regulatory approval or validated PeRSo units as a whole, and/or the constituent components, so as to comply with the relevant Standard for personal respiratory equipment. Final quality assured PeRSo units' intended use is in a health care setting. PeRSos should not be used in an industrial or manufacturing environment, drilling, welding, close to flames, chemicals or fumes or otherwise where existing, if similar looking, products would be more suitable.

Individuals should not rely on the information in this specification and attempt to self-assemble their own PeRSo. They should seek to purchase a quality assured PeRSo device from a reputable manufacturer who provides safety warnings, use instructions, gives product liability assurances, guarantees and has effective product liability insurance in place. There is an increased risk of contamination by individuals untrained in specialist donning, doffing and cleaning protocols. Any individual's use of self-made PeRSo is entirely at their own risk.

Manufacturers taking forward the production of PeRSo do so at their own risk. Manufacturers will need to develop their own manufacturing specification and undertake or obtain the necessary quality assurance, regulatory approvals, CE marking and/or compliance to the appropriate Standard prior to supplying or selling any PeRSo or releasing onto the market. Manufacturers should also undertake their own intellectual property freedom to operate checks and have in place appropriate product liability insurance.

Organisations using PeRSo or related devices should establish careful protocols for "donning", "doffing" and cleaning to prevent these devices being a source of contamination to individuals.

\section{DISCLAIMER}

Except as represented here the Specification for the PeRSo Prototype is provided "AS IS". The University of Southampton gives no assurance, guarantee or warranty, express or implied, that any PeRSo device manufactured or assembled following this specification: will be safe to use; will be of merchantable quality; will be fit for any particular purpose; will protect individuals from contracting COVID-19 or any other infectious disease or virus whilst using it; or that individuals using it will not suffer personal injury or death. The University of Southampton does not warrant or in any way assert that the manufacture, sale or use of PeRSos will not infringe the intellectual property of any other person or organization. The University of Southampton hereby disclaims any and all warranties, express or implied, and excludes, to the maximum extent permitted by law, any and all liability for any loss, harm, damage, injury or death suffered by any person caused by, or resulting from, their reliance on the information, designs and Specifications provided. 